\title{
Brand New Milk Tea Market: Chinese Milk Tea Development and Brand Analysis
}

\author{
Wingnam Shi ${ }^{1, \dagger}$ Chongxin Yang ${ }^{2, \dagger}$ Pengjun $\mathrm{Yu}^{3, *, \dagger}$
}

\author{
${ }^{1}$ Shanghai YKPao School, 200000, Shanghai, China \\ ${ }^{2}$ Management School, Lancaster University, LA1 4YW, Lancaster, UK \\ ${ }^{3}$ Alfred Lerner, University of Delaware, 19711, Newark, U.S. \\ *Corresponding author. Email: pengjun@udel.edu \\ ${ }^{\dagger}$ These authors contributed equally.
}

\begin{abstract}
Since the beginning of the 20th century, the milk tea industry grew rapidly in China and has become a popular leisure activity for young people. According to the study of three chain stores in China, low-end milk tea stores are inexpensive and affordable, while mid-range milk tea stores have a wide variety and high-end milk tea stores focus on visual effects. The core competitiveness of enterprises could be the ability to continuously push new products and supply chains. Some top brands with perfect supply chain systems save transportation costs, improve efficiency to ensure brand competitiveness. Besides, product innovation and broadening sales channels are beneficial for enterprises to find growth points in homogenized markets and better attract consumers and carry forward Chinese tea and beverage culture. After analysis, the future milk tea market will implement personalized and branded development and the emergence of chain franchise-based store opening mode. While the entire industry has unlimited prospects, there will be a lot of space for development. The results indicate that the milk tea industry will continue to expand in the future, in which innovation and personalization will be necessary to stand out. The milk tea stores will probably implement more diversified cooperation models or research more distinctive products in the future.
\end{abstract}

Keywords: Milk tea, Future trends, Marketing, Branding, Management

\section{INTRODUCTION}

With the continuous improvement of residents' living standards in China, watching movies, gatherings, shopping, and other leisure and entertainment activities have become an important part of people's lives. As a fashionable and leisure consumption drink, milk tea has become indispensable for consumers in leisure and entertainment and is deeply loved by them. Milk tea has a history of nearly 20 years in China. At the beginning of the 20th century, milk tea began to enter the field of vision of consumers initially. It was mainly fresh milk tea made with hot water to directly brew tea powder. As consumers' demands and the overall increase in economic income levels, milk tea has gradually changed to barrels and hands-shaking. In the current Chinese milk tea market, the model of "milk tea + other tea drinks" is considered new milk tea brands, which has gradually become popular and turned mainstream. Compared with powdered milk tea, the new tea drink after several improvements uses high-quality tea, fresh milk, sucrose, rich fruits and other raw materials to cater to consumers' increasingly consumption needs in aspects of health and fashion. At the same time, with the rapid development of social media, it has played a prominent role in promoting the growth of new tea drinks. New-style tea drinks emphasize beauty in product and store design, and conduct word-of-mouth communication and marketing events on social media. During the 20-year development period, with the rapid influx of capital and the expansion of top brands, the overall industry began to enter branding and many consumer industry analysts believe that it is in a highgrowth industry dividend period.

In addition, this emerging milk tea industry is developing rapidly in China and becoming more and more popular among consumers internationally. Major brands have begun to expand abroad, including Southeast Asia, Europe, America. The development of brands is also becoming more and more professional, for instance, they start to set up self-pickup cabinets, 
developing brand peripheral products, etc. The overall industry has great potential and vitality.

Ong et al. analyzed consumer preferences for milk tea attributes using an orthogonal design and found that customers were most concerned with pearl size and sugar level, least concerned with brand. According to a survey conducted by ONG et al. on the age of milk tea store customers, it was found that $88 \%$ of them were between 19-34 years old [1]. Saesieo likewise conducted an analysis of milk tea store customers in Bangkok. According to the results of a sample of 400 respondents, the majority of milk tea customers are women and are very concerned about pearls and sweetness [2].

Choi and Lee used a predictive mapping task to do a quantitative consumer test. The purpose of the study examined how customers' flavor, acceptance, and taste perception of milk tea were influenced by extrinsic cues [3]. Van analyzed the milk tea market in Vietnam in a quantitative research with 7 latitudes, including perceived quality and brand image. The final conclusion is: the largest impact comes from the shop location while customer service has the smallest impact on milk tea selection [4]. Brenda and Aun studied the milk tea market in Malaysia through quantitative analysis and concluded that consumers would pay more attention to price and brand perception when making decisions [5].

Guzman et al. used a descriptive design to investigate the influence of marketing strategies of milk tea stores on consumer preferences. By gathering the results in data, Guzman et al. found out the most appealing marketing strategy was branding as it can leave the customer a good impression. Along with marketing strategies, the location and prices also influence consumer preferences [6]. Zhang collected customer data by questionnaires and explored the relationship between customer value and customer loyalty in the Chinese milk tea market. The results of these tests showed that loyalty increases when customer satisfaction is above average and that customers will only be satisfied with milk tea that they perceive as having functional, emotional and social value, thus affecting loyalty [7].

Zhong et al. used Porter's Five Forces Model analysis method to find out the competition among companies in the milk tea industry. Zhong documents that milk tea stores should focus on innovation, health, brand and customer experience. Additionally, milk tea stores can use social media to attract customers [8]. Wu studied the hunger marketing of "A Little Bit" by using 165 questionnaires and found that hunger marketing can increase customers' perceived value of pearl milk tea and therefore influence their purchasing decisions [9]. Han compared Alittle Tea with CoCo milk tea and found that Alittle Tea pays more attention to the elements of products, with strong personalization of milk tea taste, focusing on ingredients, sweetness, and hot and cold control, Alittle Tea's ordinary milk tea price is lower than CoCo, but the price increases with the increase of ingredients [10].

The objective of this paper is to analyze the milk tea market in China. It includes a detailed analysis of the current status and environment of the milk tea market, such as the current technology of milk tea and some policies of milk tea stores. The representative stores of each of the three classes are taken out to investigate the business models and characteristics of various milk tea stores. Finally, forecasts are presented for the overall milk tea market.

\section{PEST ANALYSIS}

\subsection{Political}

Starting from 2015, with revolutionary product innovation and rapid development of social media, the milk tea industry has grown by leaps and bounds. According to data released by the National Bureau of Statistics on July 15, China's GDP grew by $6.3 \%$ in the first half of this year, of which consumption contributed more than $60 \%$, continuing to be the first driver of economic growth. In this, the night economy's importance and huge potential are striking, so the Chinese government has started to push the night economy in recent years. The milk tea industry occupies a large part of the nighttime economy and has a great advantage and opportunity in this policy. In order to meet this policy, the milk tea industry can try to support the business district in the location and extend the business hour.

In addition to pushing the night economy, the State Administration of Market Supervision adjusts the homemade beverages made for sale business project. The draft for comment on the milk tea industry is a major benefit, only simplifying the food business license application materials and compressing the food business license processing time frame. Among them, the licensing department to make the administrative licensing decision time limit compressed to 10 working days; licensing department to issue food business license time limit compressed to 5 working days. This will promote the speed of the entire market to develop rapidly while also reducing the burden on enterprises, a better business environment. Nanjing City Xuanwu District Food Section Chief Luo Yaling explained that "the previous food business project is divided into many kinds, but we found in the actual law enforcement is not very meaningful, there are some instead of adding trouble to the operator." This also shows that the changes to the whole milk tea industry is very beneficial, but also for the convenience of the entire market. 


\subsection{Economic}

Milk tea belongs to mass consumption. According to Figure2, among all the customers, the post-80s and post90 s teenagers are the main ones, and they occupy $87 \%$ of the milk tea market. According to Figure 1, sixtyfour percent of people buy milk tea from $\$ 15-24$, a price that is not a big burden for teenagers and is within their psychological tolerance. This price point is not too high and also makes milk tea an affordable drink, which also fuels the development of the dairy farm industry.

Until 2019, the number of milk tea stores has increased tremendously in major cities, and the third-tier cities even grew $138 \%$, which shows the rapid development of the milk tea industry, and also drives the economy of the entire diet industry. So far, diet is the biggest driving force to pull the Chinese economy, and the annual sales of the milk tea industry is also increasing at a rate of more than $20 \%$ per year, with an annual profit of more than 20 billion, which is developing in a good form and is gradually becoming more scaled up.

According to Figure 3, there are more than 140,000 domestic food and beverage enterprises whose business scope includes milk tea, of which 66,800 are surviving and in business. Among the above 66,800 enterprises, 11,700 have been established for more than 5 years, 13,600 milk tea enterprises have been established for 35 years, nearly 11,200 milk tea enterprises have been established for 2-3 years, and the most established for 12 years, with a total of 30,300 .

In the current milk tea market, HeyTea and Nayuki tea are considered as head enterprises. HeyTea completed its Series A financing on August 22, 2016, its Series B financing on April 25, 18, and its Series C financing on March 23, 2020, with a valuation of up to 16 billion yuan. Naiyuki announced the completion of Series C financing with the participation of PAG Taimeng Investment Group and Yunfeng Fund on January 4, 2021, with a valuation of 13 billion yuan. As mention above, it reveals that the milk tea industry is a very good earning industry with low costs and high profits, and it is estimated that it will develop rapidly in the future, but it may also increase a lot of competitors as a result, so that its industry may encounter a certain bottleneck after rapid development. Because the milk tea taste is generally the same, so the newly opened milk tea store wants to get a foothold in the industry becomes particularly difficult.

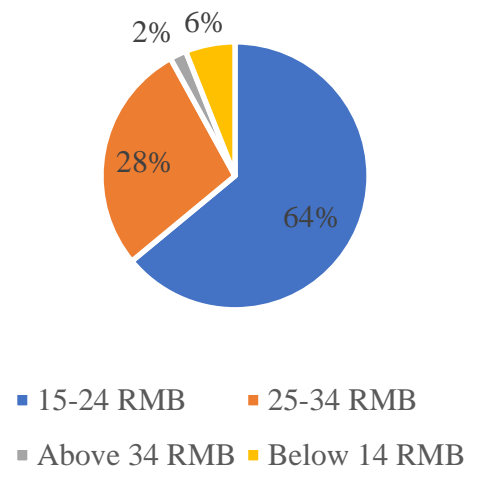

Figure1. Most Popular Milk Tea Prices

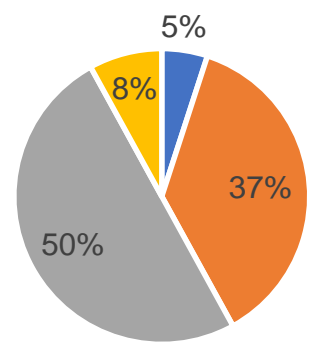

- Post-70s - Post-80s - Post-90s - Post-00s

Figure 2. Milk tea purchase age survey

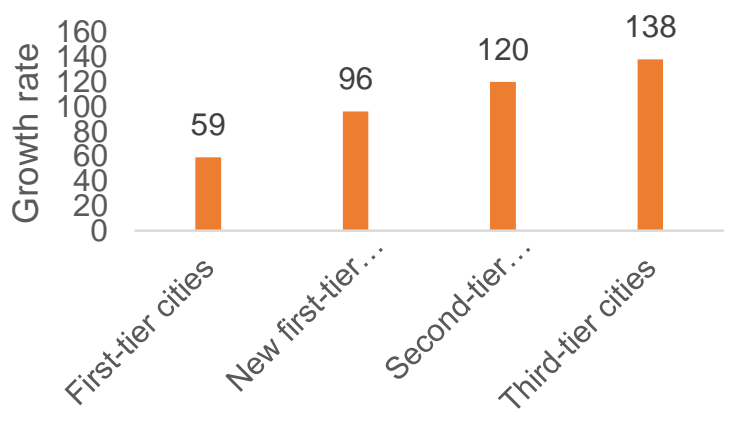

Figure 3. Milk tea store growth number growth rate situation

\subsection{Social}

According to research by CITIC Securities, close to $60 \%$ of milk tea store customers will be women in 2020(Figure 4). This directly affects the marketing strategy of most milk tea stores and the way they socialize with their customers. For example, Hey Tea focuses on attracting female customers by making drinks in various colors to attract customers and provoke them to buy and take pictures of the products. This has allowed HayTea to get far more heat and 
ratings in 2019 than any other peer (Figure5). The fourth-ranked CoCo milk tea and fifth-ranked Alittle Tea milk tea store's drinks are significantly more unpretentious than those of Hey Tea.

In addition to relying on brightly colored drinks to attract customers, Hey Tea has also launched a daydreaming program. The pure white store decoration and the peculiar tables make it irresistible to girls, and it has become one of the must-see places for photos.

Over and above using appearance, MIXUE Icecream\&Tea had also set fire to all major Chinese social software through a brainwashing song. In Bilibili, a famous animation website, the theme song of MIXUE Icecream\&Tea has over 17 million views. More than eighty-seven million people use this theme song on the short video platform TickTock, which does not include covers as well as remixes. When a rainstorm occurred in Zhengzhou, China in July 2021, MIXUE Icecream\&Tea generously donated twenty-two million dollars. Such action has impressed the general public and improved its reputation, generating moral capital. This also caused long lines to form in front of MIXUE Icecream\&Tea's store, with people wanting to make a modest donation to the effort. The measurement is certainly a very successful social strategy.

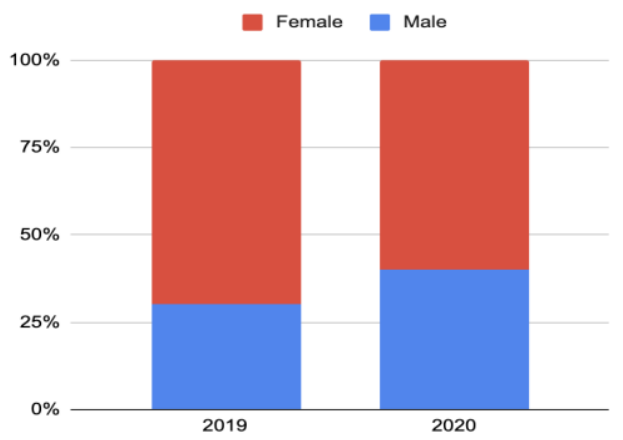

Figure 4. Ratio of male to female customers in tea stores in 2019 and 2020

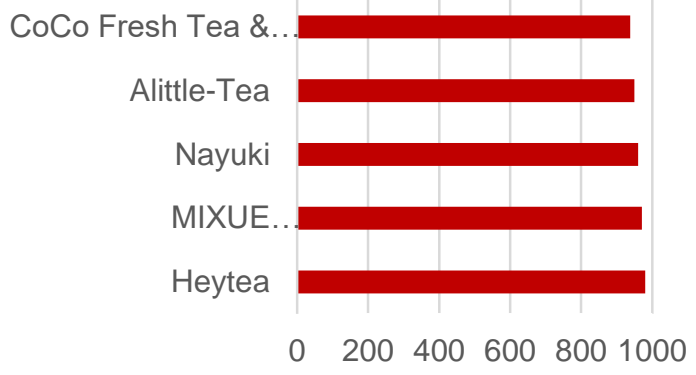

Figure 5. Top five ranking of China's tea drink store brand power in 2020

\subsection{Technology}

Ten years ago, most milk teas were brewed with milk tea powder, so the only equipment needed to make milk tea was a water heater and a sealing machine, and only a small number of stores might have ice machines. Nowadays, milk tea stores basically eliminate the brewing powder and choose to brew fresh tea, and equipment is more complex because of the improvement of technology.

Nowadays, a milk tea store may have more than ten machines, which include a steam-type water boiler that can effectively control the temperature of drinks, smoothie machine, juice extractor, water purification processor, etc. Even some machines that replace manual labor include fructose dispensing machines and fruit slicing machines. All of these effectively reduce the need for employees in the store.

In addition to the evolution of equipment, the ingredients of milk tea are also being updated. 1987 saw the birth of the first pearl milk tea, followed by the rise of taro ball, coconut and red bean in Taiwan, and in 2007 CoCo introduced this milk tea technology to the mainland, and pearls, pudding, and Platostoma palustre were paired together and named the three brothers of milk tea. In 2000 the rise of cheese tea, which is also the predecessor of milk lid, was also introduced by Happy Lemon in 2009. In 2013, Sexy Tea abandoned the use of milk tea base and started to use "tea + milk + cream + chopped nuts" to form a new type of milk tea. In 2018, Heytea added brown sugar to the pearl milk tea, creating a new trend. And then the milk tea stores began to focus on the appearance of the drink and began to add dragon fruit, cherry blossoms, roses, etc. to make the drink more attractive. The form of pearls also became more diverse, such as black pearls, white pearls, sakura pearls, etc. In the future, there will probably be more exotic milk tea ingredients produced.

\section{BRANDING \& IP}

\subsection{Business Model}

MIXUE Icecream\&Tea's drinks have low prices and low profits. It relies mainly on large franchise fees for profit. Currently MIXUE Icecream\&Tea has more than 10,000 stores. The headquarters provide all its raw materials, which produces a closed loop because it has its own production base and raw material factories. MIXUE Icecream\&Tea also has the delivery of its own logistics directly to the store, which avoids unfresh ingredients and saves on logistics costs. MIXUE Icecream\&Tea also adopted a strategy of opening stores intensively, which improves the efficiency and cost of distributing materials and management. 
Alittle Tea has adopted three types of franchising. The first is a start-up store, low investment costs, takeout window format, no booth, the store's location is flexible and low market requirements. The second is a standard store to a franchise, which can have a small number of seats and a wide range of products. The third is the flagship store, compared to the first two more upscale. The first three are single-store franchises, opening a flexible store with low investment costs and low pressure. The last is a regional franchise, although the investment costs are high but also relatively greater profits.

In contrast with Alittle Tea, Heytea never does franchising. Instead, Heyteaonly does direct operations. To ensures that store managers are more committed to their stores, Heytea encourages store managers to invest in their own stores. Until the store is profitable, Heytea will be responsible for 60 percent and store manager and staff will be responsible for 40 percent. After the profit, Heytea will receive 40 percent of the profit, and the store manager and staff will receive 60 percent of the profit. If the store is losing money, Heytea will bear 70 percent and the store manager and staff bear 30 percent.

Table 1. Different Franchising/Operation Fee(CNY)

\begin{tabular}{llll}
\hline Name & $\begin{array}{l}\text { MIXUE } \\
\text { Icecream\&Tea }\end{array}$ & $\begin{array}{l}\text { Alittle } \\
\text { Tea }\end{array}$ & Heytea \\
\hline $\begin{array}{l}\text { Business } \\
\text { Model }\end{array}$ & Franchise & Franchise & Operation \\
Franchise Fee & $50,000-100,000$ & 50,000 & 20,000 \\
$\begin{array}{l}\text { Equipment } \\
\text { Fee }\end{array}$ & 60,000 & 30,000 & 30,000 \\
$\begin{array}{l}\text { Raw Material } \\
\text { Fee }\end{array}$ & 50,000 & & \\
Water \& & 1000 & 20,000 & 80,000 \\
Electricity Fee & & & \\
Total & $172,000-222,000$ & 160,000 & 142,000 \\
\hline
\end{tabular}

\subsection{Characteristics}

MIXUE Icecream\&Tea has always adopted the strategy of selling more at a lower price. The stores are generally small, and the raw materials and packaging are low cost. MIXUE Icecream\&Tea cooperates directly with the tea producers and processors, saving the middleman price gap and the material price is twenty percent lower compared to the same type. As MIXUE Icecream\&Tea almost monopolized part of the brand raw materials, other milk tea stores that want to buy the same products can only buy at a higher price. This is also the secret of MIXUE Icecream\&Tea to be able to sell products at a very low price all the time.
ALittle-Tea focuses more on the variety of drinks compared to other milk tea stores. Its drinks are made with different tea soup as the base of milk tea, and customers are free to add different ingredients to produce a variety of combinations. Customers often share their delicious ALittle-Tea milk tea combinations on social media platforms, which saves the firm's advertising costs. And while the cashier at a typical milk tea store will only ask about the size of the cup when the customer orders, the cashier at ALittle-Tea will ask more detailed questions about the amount of ice and sweetness and whether to add ingredients. The most competitive part should be that many of the toppings are added for free, such as red beans, Platostoma palustre and pearls, which can certainly attract many customers and increase customer loyalty.

Heytea pays high attention to aesthetics. This includes the store's design, takeaway bags and product packaging. Heytea focuses on the premium market, and the stores are larger and more upscale than other ordinary milk tea stores. Special rotating lids are designed for drinks with milk caps so that consumers can drink the lids more easily. Heytea also focuses on the customer experience. During the epidemic, a special Heytea Go store was set up with no cashier, and consumers can order in a small program and then pick up their drinks at the smart tea pickup counter.

\subsection{Brand Positioning}

MIXUE Icecream\&Tea focuses on the low-end market. The price is basically less than $10 \mathrm{RMB}$, very suitable for those who have no income or lower income of students and workers. These customers don't care about the brand but the price. MIXUE Icecream\&Tea stores are mainly opened in second-tier cities. Its main products are ice cream and tea, and the $3 \mathrm{RMB}$ ice cream attracts a lot of customers. Even though MIXUE Icecream\&Tea's tea is inexpensive, its ingredients are not brewed with powder but with tea bags, which can ensure the taste and health of the drink.

Alittle-Tea focuses on the mid-range market, with an average price of around $15 \mathrm{RMB}$. It specializes in attracting customers who are worried about the unsafe price of underpriced milk tea and do not want to buy high-end milk tea. ALittle-Tea is brewed with tea leaves except for some cocoa drinks and lemon juice type which are brewed with powder. This is the reason why ALittle-Tea is able to beat other milk tea stores of the same type. ALittle-Tea's main products are milk tea and milk caps and insists on green and healthy drinks.

Heytea's main customer group is young people, generally between the ages of 18-25. Positioned as a high-end product, the price is more expensive compared to most milk teas, with an average price of about 30 RMB. Corresponding to high prices, the raw materials 
are also better. Heytea is very visual, compared to ordinary milk tea stores that all have the same stores, Heytea has many theme stores including black and gold, pink and white themes. Heytea's main product is cheese freshly brewed tea, but also will be launched in seasonal limited editions.

\section{MANAGEMENT}

\subsection{Supply Chain Management}

Under the background that products are easy to be copied, the core competitiveness of an enterprise comes from the ability to continuously push new products and supply chain. It is a key element for a company to lead in launching delicious and explosive products to occupy the consumer market.

At present, all major head brands have achieved direct source procurement in the supply chain, and they have a complete digital supply chain management system. It provides strong support for ensuring product quality and supply and implementing new product development and design.

The three most important raw materials for making new tea drinks are dairy products, fruits, and tea. Dairy products are highly industrialized, and high-quality imported milk is usually used. Fresh fruits are not easy to store and transport, so they are mainly picked directly at the place of sale. As a typical agricultural product, tea has unstable quality, and the output of famous and highquality tea that meets the taste requirements is small. Therefore, the top brands of new tea drinks often build their own tea gardens or establish cooperative relationships with tea merchants in many places to ensure the stable supply of tea raw materials.

HeyTea has established a digital supply chain management system earlier and has realized digitalization from suppliers, warehouses, transportation, distribution to production, which optimizes the efficiency of the supply chain. MIXUE Icecream\&Tea has a self-built logistics distribution system, which saves logistics costs for the supply of products, materials and equipment. At the same time, they often obtain raw material prices lower than dealers by leveraging the bargaining power brought by centralized procurement, reducing supply chain costs.

On the contrary, as for Sexy tea, because of the imperfect supply chain, some of the raw material suppliers come from overseas, so quality inspection, logistics and other links have increased the costs of refined management and the risk of raw material substitution under the reputation is too high, so the new warehouse distribution after expansion System construction has become the key to ensure efficiency.

Ensuring quality and efficiency through supply chain management is the key to the competition of existing tea drinks, which provides a guarantee for the new tea industry to build a strong brand value.

\subsection{Product development management}

In recent years, top brands have increased investment in research, development and established a rapid response innovation mechanism. HeyTea has a product development department. Most of the employees are transferred from endogenous first-line shop assistants. In addition, there is also a dedicated brand department (such as "Tao Tao"(peach) and "Mei Mei"(strawberry)).

The research and development of new milk tea can be divided into two stages: "conceptual design" and "landing design". The conceptual design first clarifies the product category (fruit tea/milk tea), establishes the basic model of the products, and clarifies the bottom, middle and top of the products. Then specific for each part. In the "landing design" part, the basic SOP is implemented according to the previous conceptual design. The product modification details are made according to the SOP, and finally the finished product is sold in stores to obtain customers' feedback.

Product research and development and continuous innovation can establish technical barriers and open up new growth points in the homogeneous product market, meet diversified consumer needs, and continue to attract more customers. With the support of strong product research and development, the research and development speed of new products in the new tea market is faster than that of traditional drinks.

\subsection{Sales channel expansion}

In 2014, MIXUE Icecream\&Tea officially opened its first overseas store in Hanoi, Vietnam. On June 22, 2020, according to official website information, MIXUE Icecream\&Tea have opened 10,000 stores worldwide. On the other hand, Hey Tea, Nayuki, etc. have already started overseas expansion attempts. At present, overseas customer groups such as overseas students are relatively large. The expansion of Taiwanese tea companies has verified the demands for tea in overseas markets and has also promoted the promotion of freshly made tea drinks overseas. The overseas market is expected to become an important support for the second expansion of mainland tea top brands.

This can help companies to further expand their business lines and diversify categories based on high brand premiums, while at the same time seeking overseas expansion to fully release brand value. In addition, as a brand-new beverage, new-style milk tea can not only promote our Chinese tea drinking culture overseas, but also the brand-new beverage model has impacted the local food flavors and brought consumers 
a brand-new beverage experience, which is better attracting consumers to occupy the market and enhancing brand value provide a very good opportunity.

\section{INDUSTRY FUTURE TRENDS}

\subsection{Industry future trend forecast}

Milk tea has addictive and social characteristics, its main ingredients are tea base, syrup and fresh milk, in which tea contains caffeine and sugar to promote the secretion of dopamine, making people feel happy, so the product has addictive properties. In addition, the milk tea store to create a leisure and social space, in order to strengthen the brand image, in order to provide a better consumer experience, very social characteristics. The addictive and social nature of milk tea has also contributed to the rapid development of the milk tea market, and therefore the long-term growth of the milk tea industry is vast. According to CBN Data, China's ready-made tea market is forecasted to be about 113.6 billion yuan in 2020 and is expected to be 340 billion yuan in 2025, with a CACR of $24.5 \%$. The market is stratified into high, medium and low end, and the head brands in each grade will start to emerge.

In the future, due to the rapid development of the milk tea industry, gaining a foothold in the industry has become a major difficulty. In order to enhance the brand vitality and value, personalized development and branding development become very important. In order to develop in the milk tea industry, personalized development is very important. For instance, the prevalent "nutritious and healthy milk tea" and "blind box milk tea" are personalized development catering to the consumers' needs. In the era of milk tea, innovative milk tea can better meet the current demands of consumers, so it can be said that taking the special route and personalized development has become the future development trend of the milk tea industry. In addition to personalized development, brand development is also very important, the milk tea industry today is constantly improving and maturing, chain franchising has become the mainstream mode of opening a store for entrepreneurs today. On the one hand, because of the change of people's consumption concept, $80 \%$ of consumers today have a higher degree of trust in the brand. On the other hand, because the milk tea chain with its specialization plays the scale effect and division of labor advantage by the industry, people attach great importance to developing personalized and brand words into the future development trend of the milk tea industry.

\subsection{Media Operation and Promotion}

In nowadays internet era, the development of milk tea industry cannot be achieved without media operation and promotion. Creative media operations and publicity can help reflect the personalization and branding of the milk tea store and make it easier to give consumers memory points, thus increasing their trust and reliance on the brand and thus developing faster.

There is no more prominent media operation in 2021 than the theme song of MIXUE Icecream\&Tea. With a simple melody, catchy lyrics and massive repetition, MIXUE Icecream\&Tea theme song was memorable, thus making people remember MIXUE Icecream\&Tea. At the same time, MIXUE Icecream\&Tea also introduced a corresponding policy for customers to sing this theme song in front of the store in exchange for corresponding coupons. This preferential policy and personalized theme song also made MIXUE Icecream\&Tea explode on the internet.

In addition to the unique theme song, blind boxes of milk tea are also extremely prevalent this year, combining blind boxes with milk tea to form a unique brand style, a personalized product launched by MYGIRL. The merchants put all kinds of girls' favorite gifts at the bottom of the milk tea, among which the hidden models are small samples of cosmetics of various big brands. Many people on Jitterbug have traveled far and wide to buy a dozen cups of milk tea for the hidden models, so blind boxes of milk tea have become a new trend on Jitterbug. The cost of the blind box is not low, but the price of milk tea did not rise. The owner said, "we value the marketing value", so you can see that good marketing can bring more customer traffic and sales.

The milk tea industry is prevalent, and the future of branding and personalization cannot be achieved without media operations and publicity, by means of theme songs, blind boxes of milk tea, peripherals, etc., as well as publicity on various platforms. Media operations and publicity can help milk tea stores grow their traffic and sales, while also establishing the personalization of the brand, making it different from other stores, providing consumers with memory points and building loyalty with customers.

\subsection{Collaboration}

Chain franchise is the future of milk tea entrepreneurs to open mainstream mode, so cooperation is essential in the future development, which is mainly divided into two cooperation models, vertical integration and horizontal cooperation.

Vertical integration includes franchising in the industry, acquisition of raw material vendors, etc. The advantage is to provide a one-stop service that aggregates the traffic and technology of two milk tea stores to provide more convenient services and earn more profit at the best cost. In addition to this, the acquisition of raw material merchants can also reduce the cost of revenue and reach long-term cooperation, 
while preventing the sharing of a supplier with other businesses, which is also more conducive to the development of personalized.

Horizontal cooperation includes co-branding with other brands, acquiring other stores, etc. The co-branded peripheral can be used as a marketing tool as a way to increase awareness and sales and can also benefit both brands at the same time. Like the co-branding between HeyTea and The Fenty Beauty makeup set is also gaining a lot of popularity, with limited peripherals to gain consumer interest.

Collaboration, whether vertical or horizontal, is a marketing tool that can be used to reduce costs, increase revenues and profits, while increasing awareness and building loyalty with consumers, leading to personalization and branding.

\section{CONCLUSION}

This article analyzes the Chinese milk tea beverage market in multiple perspectives, collects a large number of reports and data, and exploits the PEST analysis method to make a preliminary analysis of the entire market. For further in-depth analysis, this research analyzes the three major aspects from Branding \& IP, Management, and Industry future trends, involved in business model, brand positioning, competitive elements, supply chain management, future product development trend, etc.

As for consumers, the majority of consumer groups are in the 12-35 age group, of which women (55\%) account for slightly higher proportions than men (45\%) (figure4), which is not directly related to other factors such as income, occupation, and so on. However, brand positioning and brand research and development are the most important competitive factors facing consumers and the market for an enterprise. From the perspectives of taste, health, cost, price, product design, etc., through research on market demand, develop a brand-new flavor could quickly attract consumers in a homogenized market and increase brand awareness. For the internal management of the enterprise, product operation and supply chain management are of great importance. Supply chain management could improve the production efficiency of the store, while saving the entire transportation cost, and the operation could be divided into marketing methods, combined with new media to promote brands and products, etc. Specifically, stores could increase customer loyalty by collecting stamps for free drinks, promote their own brand's single products through short video platforms, and establish a peripheral system, such as launching theme songs and limited-edition teacups to increase brand value. In addition, it could also improve the online ordering system, visually attract consumers through the image design of the single product and improve the shopping experience.

In the last part of the analysis, it has made a preliminary analysis of the future trend of the industry. In China, milk tea has been developed for 20 years. In the past, there were not so many types of milk tea. Most of them consisted of hand-cranked milk tea and pearls. At the same time, the shops selling milk tea were separate. For now, the whole market is showing a branding trend, and it is becoming more and more sophisticated. For future development, the overall market development trend should be positive. However, in addition to perfecting branding for individual enterprises, there are two important points to pay attention to. First, avoid negative news. When selecting raw materials, in addition to controlling costs, there must be a health guarantee. Otherwise, once negative news appears, it will cause very large losses to the brand image and value and even affect the development of the entire industry, resulting in consumers reluctant to buy such products. Second, in a homogeneous market, cooperation is an important innovation breakthrough. This is reflected in the cooperation between industries and in cross-industry cooperation, such as cooperation with the famous brand Starbucks in the coffee industry. Launching a co-branded peripheral, or assuming the launch of a milk tea-making machine with the same functions as a coffee machine to change people's consumption habits and improve the experience of drinking beverages, which will provide a very good opportunity for companies to better occupy the market.

In summary, milk tea beverages are an industry with great development opportunities. Every company should catch and cherish these opportunities. While perfecting branding, it should look for higher innovation breakthroughs to increase market share.

\section{REFERENCES}

[1] Ong, A. K. S., Prasetyo, Y. T., Libiran, M. A. D. C., Lontoc, Y. M. A., Lunaria, J. A. V., Manalo, A. M., ... Persada, S. F. (2021). Consumer Preference Analysis on Attributes of Milk Tea: A Conjoint Analysis Approach. Foods, 10(6), 1382.

[2] Saesieo, S. (2016). Factors affecting buying decision of pearl milk tea in Bangkok. The Journal of Graduate Studies at the University of Suanta2(1), 11-21.

[3] Y Choi, \& Lee, J. . (2019). The effect of extrinsic cues on consumer perception: a study using milk tea products. Food Quality and Preference, 71, 343-353.

[4] Van Dung, H. A. (2020). Determinants of Milk Tea Selection in Ho Chi Minh City. American Journal 
of Multidisciplinary Research \& Development (AJMRD), 2(4), 23-28.

[5] Wen, B. L. J., \& Aun, N. B. (2020). Factors Influencing consumers' purchase intention in Klang Valley, Malaysia: A Study of Bubble Milk Tea. BERJAYA J. Serv. Manag, 13, 29-43.

[6] Guzman, M. D., Deramas, L., Faustino, J. R., Lopez, N., Lorenzo, A., \& Santos, J. (2020). The Influence of Marketing Strategies of Milktea Shops on the Preference of the Consumers. Social Science Research Network.

[7] Zhang, Y. (2020). How customer value affects customer loyalty in milk tea market in China.
[8] Zhong, Sun, Cheng, Joon, Wang, Zihan, Zou, JiaLi \& Zhang, Murong. (2020). Milk tea industry market analysis report. Industrial Science and Technology Innovation (01), 63-64.

[9] Wu, Z. (2020). Clarifying the impact of hunger marketing strategy in buyers' purchase behaviors of bubble milk tea (Doctoral dissertation).

[10] Han, Y. (2018, August). Study on consumption behavior of milk tea based on the customer value theory-Taking "A little tea" in Shenzhen as an example. In Proceedings of the 2018 International Conference on Management, Economics, Education and Social Sciences (MEESS 2018), Shanghai, China (pp. 11-12). 